\title{
Renovating the excitation circuit of a conventional welding converter
}

\author{
GULDEREN YILDIRMAZ*, M HADI SARUL, REMZI GULGUN \\ and HULYA OBDAN
}

Yildiz Technical University, Electrical-Electronics Faculy, Electrical Engineering Department, 34349 Besiktas, Istanbul, Turkey

e-mail: \{gyildir, sarul, gulgun, obdan\} @ yildiz.edu.tr

MS received 25 November 2004; revised 18 January 2006

\begin{abstract}
This paper presents two different new excitation current supplies based on power electronics for an existing conventional welding converter. The proposed circuits are simulated using Lab-VIEW $1200 \mathrm{AI}$ and a PC based system. In the expressions for winding currents the dynamic inductances are used to take into account the saturation in the core of the winding. The experimental circuits are implemented and tested. The percentage peak-to-peak ripple currents are calculated for both simulation and experimental results and for both circuit configurations. The results are summarized in two tables for comparison.
\end{abstract}

Keywords. Welding converter; dynamic inductance; phase control; duty cycle control.

\section{Introduction}

In electric arc welding, the melting energy is provided by establishing an arc between two electrodes. One of the electrodes is the metallic workpiece being welded. It is desirable to have a very low ripple in the current once an arc is established (Weisman 1976; Elect. Eng. Hand book 1985). It is important to distinguish between constant current (CC) and constant voltage (CV) electrical welding systems. Shielded metal arc welding (SMAW) and gas metal arc welding (GMAW) are always performed with a CC system. The current flowing through the electrode and the workpiece is a primary variable in determining heat input. For SMAW on CC systems, the machine setting determines the basic current rate (amperage), although changes in the arc length further change the current rate. Longer arc lengths reduce the current rate. The arc voltage is determined by the arc length, which is manipulated by the welder. The voltage of a welding circuit is composed of the arc voltage and a series of voltage drops (Miller 1999).

In all welding applications, the output needs to be electrically isolated from the mains input. The modern arc welding converters of today are always of the semiconductor-type,

${ }^{*}$ For correspondence

A list of symbols \& abbreviations used is given at the end of the paper 
where this electrical isolation is provided by either a supply frequency power transformer or a high-frequency transformer. The solution with supply frequency power transformer suffers in weight, size and losses. The switch-mode welder, which uses a high-frequency transformer for electrical isolation, has much smaller size, weight and higher efficiency compared with the welders employing a supply frequency power transformer (Mohan et al 1995).

The semiconductor welding equipment is of the DC type, just as earlier welding generators used to be. A comparison of these two types of welding equipment invariably turns out in favour of the semiconductor-type, from both the technological and economical viewpoints. The semiconductor welding equipment has lower no-load loss and higher efficiency; it has no moving parts except for the cooling fan, so that its lifetime is long and its maintenance requirement is low, and it is also more resistant to detrimental influences of the environment (Csaki et al 1995).

However, there are exceptions in some welding applications, such as in gas tungsten arc welding (GTAW). An AC arc is ideal for GTA welding of aluminium. The positive half cycle removes the aluminium oxide, while the negative half cycle heats the workpiece (Stava 1999). With the traditional AC sine wave, there is gradual change from the maximum value to zero (no arc), then gradual build-up to maximum negative value. This gradual decay and build-up makes it difficult to reignite the arc after it extinguishes at the zero point. In recent years, new squarewave power sources have been developed to overcome this phenomenon (Klingman 1998).

Different power sources are needed normally for steady DC welding and for pulsed DC welding. Nowadays, research is directed to the new welding power sources, which enable both steady DC and pulsed DC welding to be performed (Thamodharan et al 1999). Otherwise, plasma cutting requires much higher voltage with much lower current compared to arc welding. Because of this distinction, arc welding and plasma cutting have always been performed using different power sources. But metal fabrication often needs both arc welding and plasma cutting. For this purpose a universal power source capable of powering both processes has been developed (Zhang \& Zhang 1998; Sarul et al 2000).

Conventional welding machinery, like the general-purpose generator converter, which has a very poor performance, is still used in industry, as they are robust and less costly. There exists in our laboratory an old motor-generator arc welding converter, the general diagram of which is shown in figure 1. It was ascertained that the generator did not produce sufficient voltage for the welding process. We intended to remove the defect. It was found that the exciting current was very low and could not be raised. There was a serious problem in the magnetic amplifier (MA). All the other parts of the converter were in good condition. In particular, the commutator of the DC generator did not have much wear. Normally the lifetime of a DC generator is limited by the wear of the commutator segments. Therefore, we decided to replace the old-technique excitation system with a simple system using power electronics. The solution was to consist in converting an AC voltage of $90 \mathrm{~V}$ to a controllable direct current. For this purpose phase control and PWM control techniques were employed. These two solutions were theoretically and practically examined.

\section{A general description of the existing direct current arc welding converter}

The old existing converter is composed of a direct current generator, a three-phase induction driving motor and a control board. The generator and motor rotors are mounted on the same shaft in the same body. Therefore, the converter has a compact construction. The welding current and operating voltage ratings for $55 \%$ duty cycle are $330 \mathrm{~A}$ and $32 \mathrm{~V}$ respectively. The 


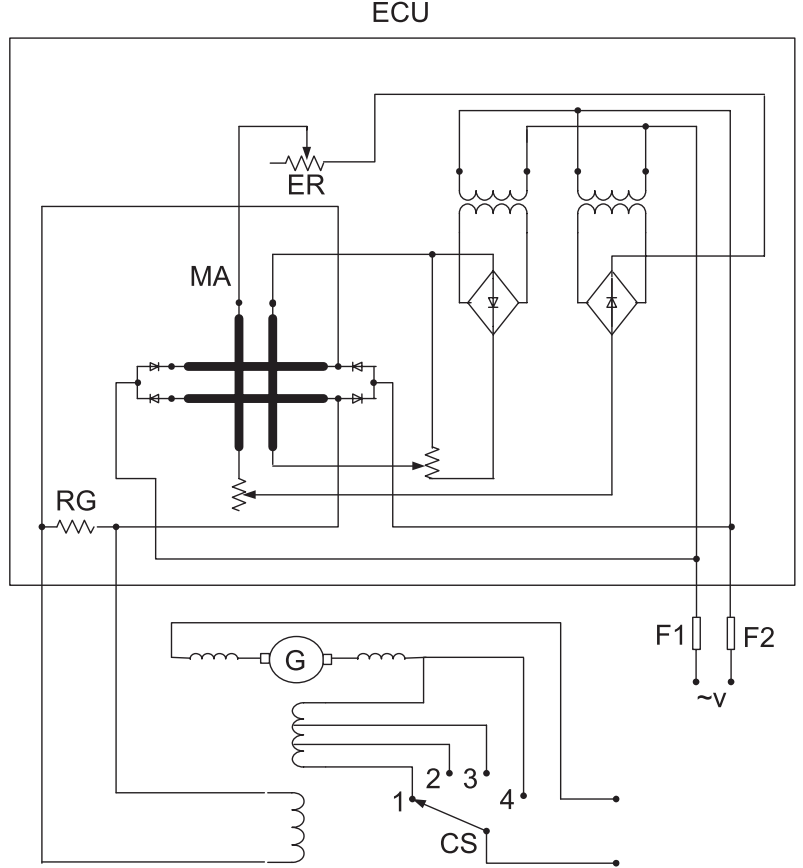

Figure 1. Basis scheme of the existing arc welding converter.

welding current has a control range of 50-370 A, corresponding to the operating voltages of $22 \mathrm{~V}$ and $34 \mathrm{~V}$ respectively. The idle running voltage is $65 \mathrm{~V}$.

The DC generator has a separately excited field winding, with 4 main poles and 4 commutating poles. The independent excitation winding is placed on two diametrically opposed excitation poles, while the differential excitation winding is on the other two excitation poles. The static characteristics become steeper with the aid of differential excitation winding. As seen in figure 1, the generator has altogether 4 control ranges by using the switch (CS) connecting the mass terminal. If no parts of the differential winding are in operation (position 4), the generator shows descending static characteristics because of armature reaction only. Static characteristics with greater slopes are obtained by taking into operation the differential winding partly or entirely. The entire differential excitation winding enters the circuit in the position (1) of (CS), and the static characteristic has the steepest slope.

The welding current is finally controlled within each control range by adjusting the current of the independent excitation winding. The adjusting is performed with the aid of the excitation rheostat (ER) connected in series with control winding of (MA). The generator idle-running voltage should be controlled with the excitation rheostat (ER) between 40-42 V at the minimum current position and between $62-65 \mathrm{~V}$ at the maximum current position. The excitation current values should be from 0.9-3.1 A at the extreme positions of (ER).

The three-phase driving induction motor has a squirrel cage and its rating for long-service use is $14 \mathrm{~kW}$. One of the stator winding phases of the motor is operated also as an autotransformer. The output voltage of this transformer used for feeding the excitation control unit (ECU) is about $90 \mathrm{~V}$. As seen in figure 1, this voltage is applied to (MA) via the fuses (F1, F2). The control board consists of a star-delta switch for starting the motor, safety fuses $(\mathrm{F} 1, \mathrm{~F} 2)$, a four-position control range switch (CS), magnetic amplifier (MA), an ammeter, a voltmeter and others. 


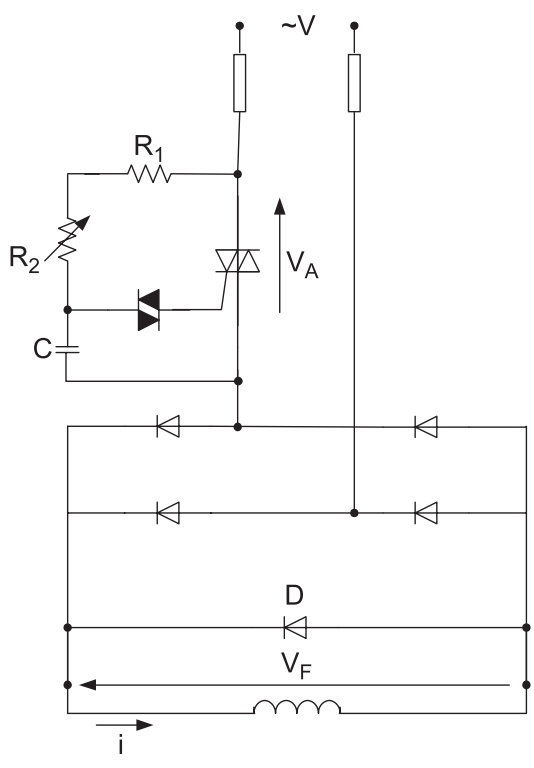

(a)
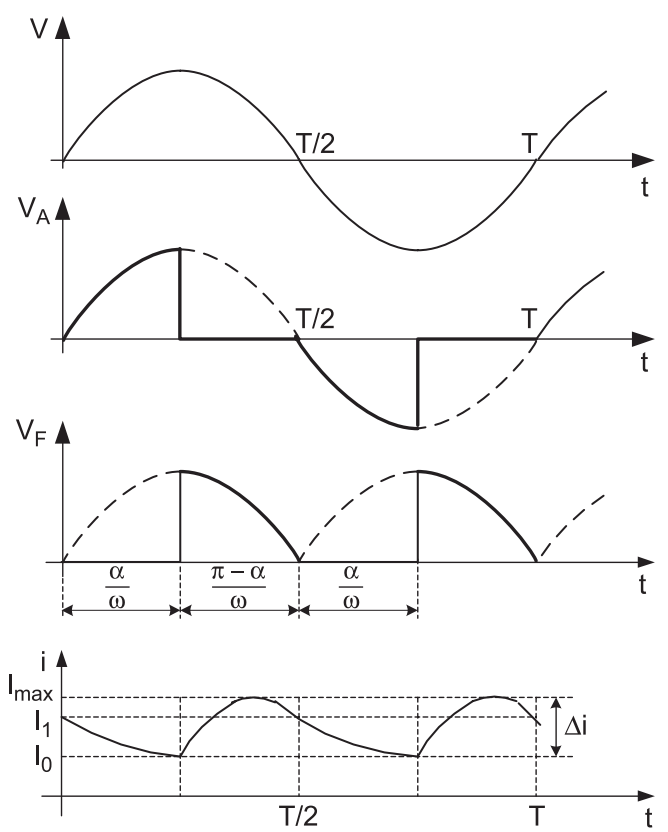

(b)

Figure 2. Feeding the excitation winding by using a phase-controlled circuit, (a) circuit, (b) waveforms.

\section{Proposed circuit configurations}

\subsection{Feeding by phase-controlled circuit}

In this paper, we proposed two different circuit configurations to feed the excitation winding of the welding converter. One of them is phase-controlled by using a triac and a diode bridge (see figure 2). We employed a triac as switching device instead of thyristors, because of the simplicity of the triggering circuit.

The excitation winding voltage $v_{F}$ can be written as,

$$
v_{F}=L \frac{\mathrm{d} i}{\mathrm{~d} t}+R i
$$

where $L$ and $R$ are inductance and resistance of the excitation winding respectively. Omitting voltage drops on the semiconductor devices, $v_{F}$ is rectified supply voltage during the on-state of the triac,

$$
L \frac{\mathrm{d} i}{\mathrm{~d} t}+R i=V_{m} \sin (\omega t+\alpha) .
$$

During the off-state of the triac the winding current flows through the diode $(D)$. For convenience, we accept our reference point as zero at the beginning of the off-period. Then the equation during the off-period (interval) will be,

$$
L \frac{\mathrm{d} i}{\mathrm{~d} t}+R i=0
$$


During the conduction period $0\langle t\langle(\pi-\alpha) / \omega$ of the triac the winding current can be obtained by solution of (2)

$$
i=A e^{-\frac{R}{L} t}+B \sin \left(\omega t+\alpha-\operatorname{tg}^{-1} \frac{L \omega}{R}\right)
$$

where

$$
\begin{aligned}
& B=\frac{V_{m}}{\left(R^{2}+(L \omega)^{2}\right)^{1 / 2}} \\
& A=I_{0}-B \sin \left(\alpha-\operatorname{tg}^{-1} \frac{L \omega}{R}\right)
\end{aligned}
$$

and $I_{0}$ is the initial winding current at $t=0$. At the instant $t=(\pi-\alpha) / \omega$ the triac takes its off-state by decreasing the rectified supply voltage to zero. The winding current at this instant is $I_{1}$ and it begins to change according to (3). Its solution for the case that the triac is in the off-state and the diode is in the on-state,

$$
i=I_{1} e^{-\frac{R}{L} t} .
$$

At the end of this switching interval the winding current that equals the initial current at the next triggering of the triac is

$$
I_{0}=I_{1} e^{-\frac{R \alpha}{L \omega}}
$$

because the on-state of the diode takes time $\alpha / \omega$.

The initial winding current $I_{0}$ increases at each on-interval of the triac and it stays constant when the steady-state condition is reached. The following relationship can be derived from (4), (5), (6), (7) for the steady-state operating condition.

$$
\begin{aligned}
\left\{\left[I_{0}-\right.\right. & \left.\frac{V_{m}}{\left(R^{2}+(L \omega)^{2}\right)^{1 / 2}} \sin \left(\alpha-\operatorname{tg}^{-1} \frac{L \omega}{R}\right)\right] e^{-\frac{R}{L} \frac{\pi-\alpha}{\omega}} \\
& \left.+\frac{V_{m}}{\left(R^{2}+(L \omega)^{2}\right)^{1 / 2}} \sin \left(\pi-\operatorname{tg}^{-1} \frac{L \omega}{R}\right)\right\} e^{-\frac{R}{L} \frac{\alpha}{\omega}}=I_{0} .
\end{aligned}
$$

Because $V_{m}, R, L$ and $\omega$ in (9) are known, the winding current $I_{0}$ can be obtained for a specific triggering angle of the triac.

The winding current takes its maximum value in the on-state interval of the triac. Then using (4) can be obtained the time $t_{m}$ at which the winding current is maximum.

$$
\begin{aligned}
\frac{\mathrm{d} i}{\mathrm{~d} t} & =0 \frac{V_{m}}{\left(R^{2}+(L \omega)^{2}\right)^{1 / 2}} \omega \cos \left(\omega t_{m}+\alpha-\operatorname{tg}^{-1} \frac{L \omega}{R}\right) \\
& =\frac{R}{L}\left(I_{0}-\frac{V_{m}}{\left(R^{2}+(L \omega)^{2}\right)^{1 / 2}} \sin \left(\alpha-\operatorname{tg}^{-1} \frac{L \omega}{R}\right)\right) e^{-\frac{R t_{m}}{L}} .
\end{aligned}
$$

We can solve $t_{m}$ from (10) and substitute $t=t_{m}$ in (4) to obtain the maximum winding current. 
The most important value of the winding current is the average value. We can obtain it by using the average winding voltage which is

$$
V_{F A V}=\frac{V_{m}}{\pi}(1+\cos \alpha),
$$

omitting the on-state voltage drops in the semiconductor devices. The average value (the DC component) of the winding current is

$$
I_{A V}=\frac{V_{F A V}}{R} .
$$

The current ripple (the percentage peak-to-peak ripple current) that depends on the triggering angle of triac, can be written as

$$
I_{p p} \%=\frac{I_{\max }-I_{\min }}{I_{A V}} 100 .
$$

\subsection{Feeding by using diode bridge and DC chopper}

As seen in figure 3, an IGBT is used as switching device in the DC chopper. During the on-state of IGBT the voltage across the winding is the rectified supply voltage. If the IGBT is turned off, the winding current continues to flow through the diode $(D)$ which shorts the winding. Then the voltage on the winding becomes zero where we omit the on-state voltage drop in the semiconductors. Therefore, (1) and (2) are also valid in this circuit configuration.

Since the switching frequency is high enough, we can assume that the voltage across the winding is constant during the on-state of the switching element. So from (1) we can write

$$
L \frac{\mathrm{d} i}{\mathrm{~d} t}+R i=V_{n A V},
$$

where $V_{n A V}$ is the average value of the rectified supply voltage during the on-interval of the IGBT in the $n$th switching period from the beginning of the supply voltage half cycle. The solution of this equation, under the initial condition $i=I_{0 n}$ for $t=0$ is

$$
i=\frac{V_{n A V}}{R}-\frac{V_{n A V}}{R} e^{-\frac{R}{L} t}+I_{0 n} e^{-\frac{R}{L} t} .
$$

At the end of the on-interval, $t=T_{1}, i=I_{1 n}$.

$$
I_{1 n}=\frac{V_{n A V}}{R}-\frac{V_{n A V}}{R} e^{-\frac{R}{L} T_{1}}+I_{0 n} e^{-\frac{R}{L} T_{1}} .
$$

During the off-state of the IGBT the winding current flows through the diode (D) and (2) is valid. The initial current at this interval $T_{2}$ is $I_{1 n}$, then the solution of (2) is

$$
i=I_{1 n} e^{-\frac{R}{L} t} .
$$

At the end of the off-interval, $t=T_{2}$ and

$$
I_{0(n+1)}=I_{1 n} e^{-\frac{R}{L} T_{2}} .
$$




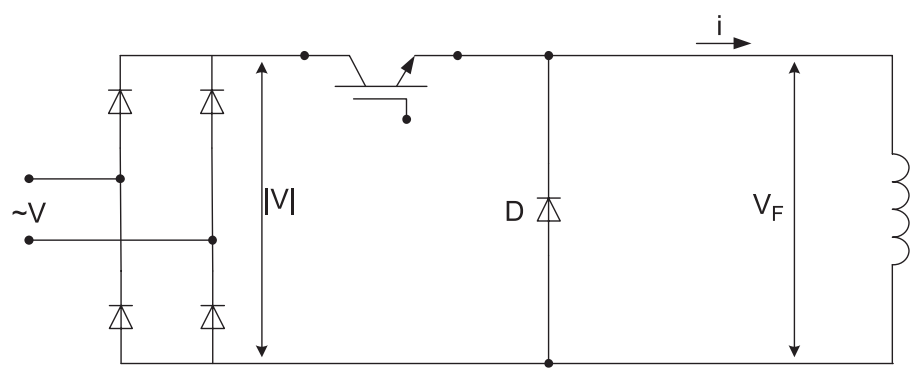

(a)
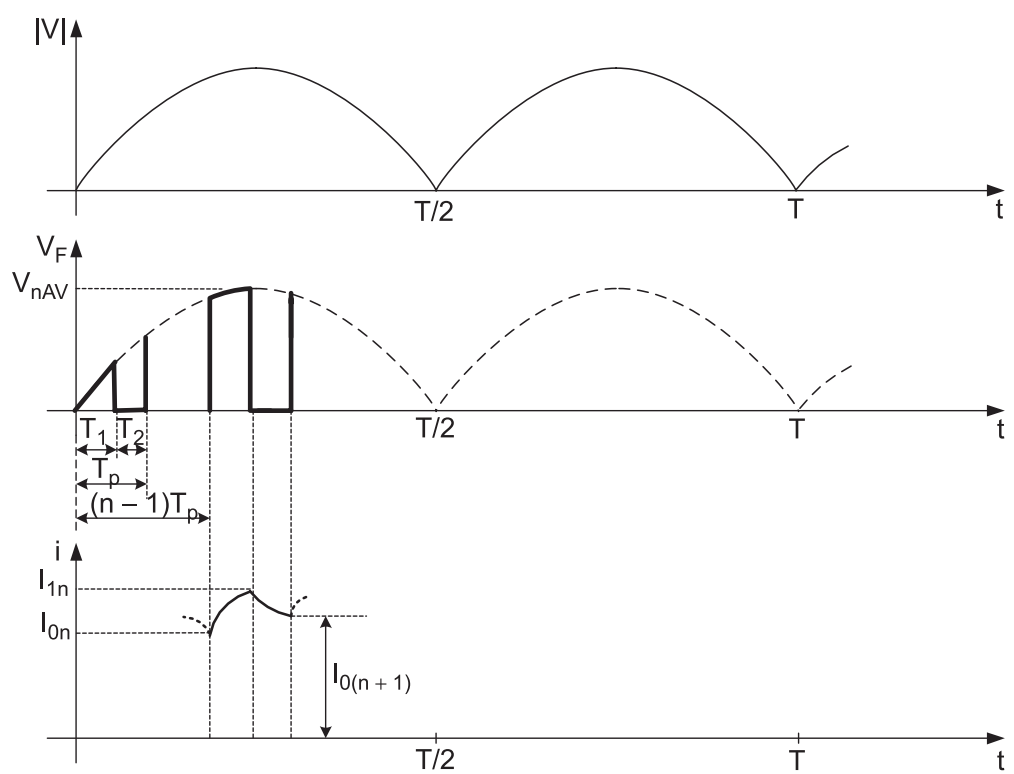

(b)

Figure 3. Feeding the excitation winding by using diode bridge and DC chopper, (a) circuit, (b) waveforms.

In every switching period a definite $I_{1 n}$ and $I_{0 n}$ value appear according to supply voltage $v$ and the duty cycle $d=T_{1} / T_{p}$ as seen in figure $3 \mathrm{~b}$.

If we assume that the first switching period begins at the zero-crossing of the voltage $v$, the winding voltage during the on-state in the $n$th switching period can be written as

$$
V_{n A V}=\frac{1}{T_{1}} \int_{T_{p}(n-1)}^{T_{p}(n-1)+T_{1}} V_{m} \sin (\omega t) \mathrm{d} t .
$$

The maximum pulse number in a half wave of the supply voltage is

$$
n_{\max }=\frac{f_{p}}{2 f}
$$

where $f_{p}$ and $f$ are the switching frequency and the supply frequency respectively. For a synchronous operation $n_{\max }$ must be an integer. 
Assuming that the circuit is switched on at $v=0$ and the pulse of the first switching period begins at $v=0$ as well, the initial winding current $I_{01}$ is zero. The current increases normally at the on-states of IGBT and decreases at its off-states. At the beginning of the next half cycle of the supply voltage, the winding current is not the same anymore. The initial current $I_{01}$ increases in every cycle of the supply voltage until the steady-state is reached. The winding current at the beginning of the supply half cycles stays constant in the steady state.

The average value of the winding current in steady state can be obtained from the average value of the voltage across the winding. The mean value of the winding voltage $v_{F}$ during an supply half period is

$$
V_{F A V}=\frac{2}{\pi} V_{m} \frac{T_{1}}{T_{p}}
$$

where $T_{1} / T_{p}=d$ is the duty cycle. And the mean value of the current is

$$
I_{A V}=\frac{2}{\pi} \frac{V_{m}}{R} d .
$$

The minimum and maximum values of the winding current can be obtained from (15) and (17) and the current ripple can be found using (13).

\section{Simulation results}

The proposed circuit configurations are simulated in phase-controlled circuits by using (4) and (7), and in the PWM-controlled circuit by using (15) and (17), and a PC system based on Lab-View 1200 AI.

The saturation in the magnetic core of the excitation winding is taken into account by using the dynamic inductances of the winding in the above equations. The dynamic inductances of the winding are measured by using a DC power supply with an adjustable voltage, a DC chopper, a PC-based measuring system containing a Lab-View card (Sarul et al 2000). The dynamic inductances measured and used in simulation in different currents are seen in tables 1 and 2 . The winding pure resistance is $16 \Omega$ and $R$ in the equations is accepted as $17 \Omega$ considering the use of the sampling resistance and ammeter.

The initial current at $t=0$ and at the beginning is taken as zero. In the phase-controlled circuit in figure 2a the initial currents in every half cycle of the supply voltage increase until the steady-state is approximately reached.

\begin{tabular}{|c|c|c|c|c|c|c|c|c|c|}
\hline \multirow[b]{2}{*}{$A\left(^{\circ}\right)$} & \multirow[b]{2}{*}{$L(H)$} & \multicolumn{4}{|c|}{ Simulation } & \multicolumn{4}{|c|}{ Experimental } \\
\hline & & $I_{A V}(A)$ & $I_{\min }(A)$ & $I_{\max }(A)$ & $I_{p p}(\%)$ & $I_{A V}(A)$ & $I_{\min }(A)$ & $I_{\max }(A)$ & $I_{p p}(\%)$ \\
\hline 68.2 & 0.96 & 3.26 & 3.110 & 3.378 & 8.2 & 3.28 & 3.11 & 3.38 & 8.2 \\
\hline 85 & 0.98 & 2.59 & 2.454 & 2.692 & 9.2 & 2.54 & 2.46 & 2.70 & 9.4 \\
\hline 101 & 1.13 & 1.92 & 1.828 & 2.005 & 9.2 & 1.94 & 1.79 & 2.00 & 10.8 \\
\hline 114 & 1.03 & 1.41 & 1.327 & 1.483 & 11.1 & 1.41 & 1.32 & 1.48 & 11.3 \\
\hline 131 & 1.02 & 0.82 & 0.761 & 0.867 & 12.9 & 0.85 & 0.76 & 0.87 & 12.9 \\
\hline
\end{tabular}

Table 1. Summary of simulation and experimental results for phase-controlled method. 
Table 2. Summary of simulation and experimental results for PWM-controlled method.

\begin{tabular}{|c|c|c|c|c|c|c|c|c|c|}
\hline \multirow[b]{2}{*}{$d(\%)$} & \multirow[b]{2}{*}{$L(H)$} & \multicolumn{4}{|c|}{ Simulation } & \multicolumn{4}{|c|}{ Experimental } \\
\hline & & $I_{A V}(A)$ & $I_{\min }(A)$ & $I_{\max }(A)$ & $I_{p p}(\%)$ & $I_{A V}(A)$ & $I_{\min }(A)$ & $I_{\max }(A)$ & $I_{p p}(\%)$ \\
\hline 20 & 1.02 & 0.95 & 0.93 & 0.97 & 4.2 & 0.80 & 0.78 & 0.82 & 5.0 \\
\hline 39 & 1.11 & 1.85 & 1.82 & 1.89 & 3.8 & 1.41 & 1.37 & 1.45 & 5.7 \\
\hline 52 & 1.00 & 2.47 & 2.42 & 2.52 & 4.0 & 1.91 & 1.85 & 1.96 & 5.8 \\
\hline 70 & 0.96 & 3.33 & 3.26 & 3.39 & 3.9 & 2.59 & 2.52 & 2.67 & 5.8 \\
\hline 85 & 0.96 & 4.04 & 3.97 & 4.12 & 3.7 & 3.26 & 3.17 & 3.34 & 5.2 \\
\hline
\end{tabular}

The initial currents in the half cycles obtained may be seen in figure 4 for the triggering angle of 101 degrees. The transient time and the approximate final winding current can be found from this figure. We had to repeat the simulation according to the final current by using the real dynamic inductance. The voltage applied to the winding and the steady-state current can be seen for $\alpha=101^{\circ}$ in figure 5. The simulation results obtained for various angles $\alpha$ and therefore for various winding currents in the case of the phase-controlled method are given in table 1. Since the winding voltage initial values are rather high within the control range of the winding current, the minimum values of the winding current are at the same time equal to its initial value. As may be seen in table 1, the current ripple increases as the winding current decreases.

In the same way, we simulated the PWM-controlled circuit for the various duty cycles (d) which give the desired winding currents according to (22). As in the case of the phasecontrolled circuit, here too, the initial current values at the beginning of the AC voltage half cycles gradually increase and, eventually when steady state is reached, become approximately constant. The way the initial current values change for duty cycle $d=0.52$, can be seen in figure 6. The initial current values at the beginning of the AC voltage half cycles increase from the start until steady state is reached. Furthermore the initial current value at the beginning of each pulse changes according to the value of the supply voltage in the half cycle. For this reason, the variation of the initial current as a function of time is seen in the form of a band in figure 6. However, we can find again the transient time and the approximate final current for a special duty cycle. In the steady-state the winding voltage and current waveforms for $d=0.52$ are shown in figures $7 \mathrm{a}$ and $7 \mathrm{~b}$ respectively. As can be seen in figure $7 \mathrm{~b}$, the

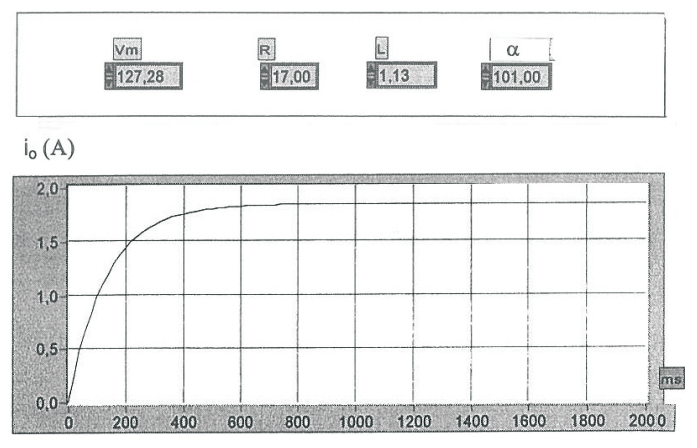

Figure 4. The initial transient winding current versus time for phase-controlled circuit obtained in simulation. 


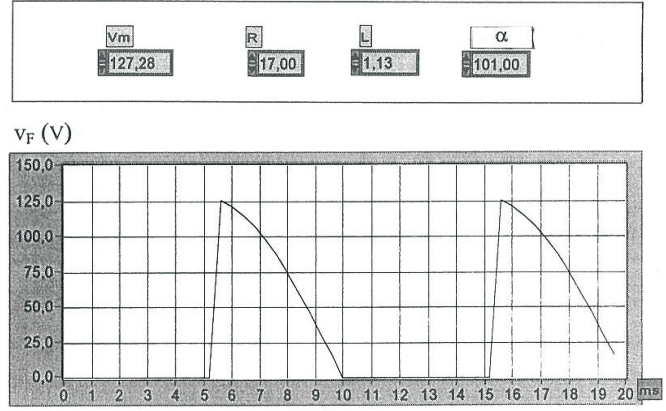

(a)

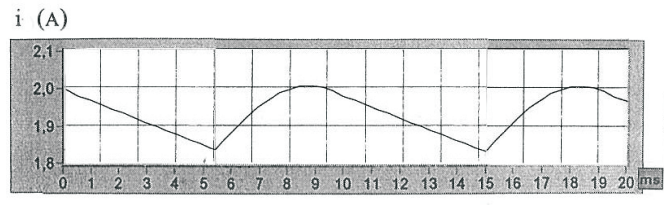

(b)
Figure 5. The simulation results obtained for $\alpha=101^{\circ}$ in phase-controlled method, (a) winding voltage and (b) winding current waveforms.

winding current also contains peaks related to the switching frequency apart from the ripple resulting from the sinusoidal voltage. The simulation results for various duty cycles and therefore for winding currents are given in table 2 . The current ripple values are calculated using (13).

We can compare phase-controlled and PWM-controlled circuit configurations using two criteria. The first criterion is the transient time and the second is the current ripple. As a comparison between figures 4 and 6 indicates, the transient time is shorter in the PWMcontrolled circuit than in the phase-controlled circuit. However, a transient time under 1 second is not important for this general-purpose welding converter. As may be seen in table 2, the current ripple in the PWM-controlled circuit is not much dependent upon the winding current. In fact, when the winding inductance is constant and if the switching frequency is selected to be very high, the current ripple can be assumed to be completely independent of the winding current.

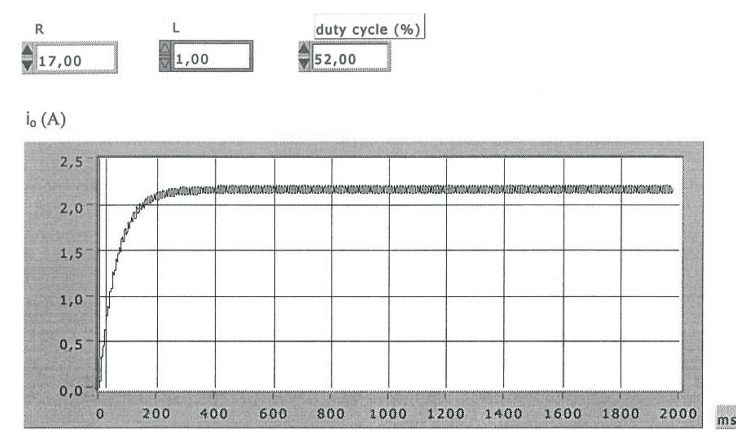

Figure 6. The initial transient winding current versus time for PWM-controlled circuit obtained in simulation. 


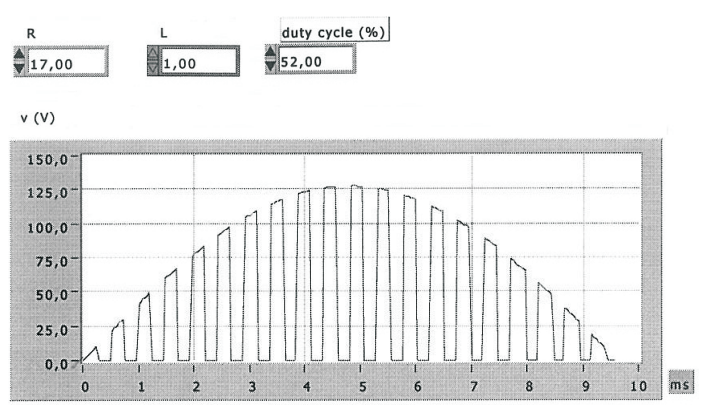

(a)

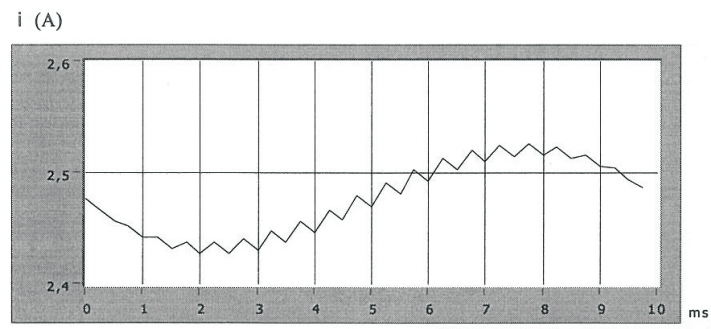

(b)
Figure 7. The simulation results obtained for duty cycle of 0.52 in the PWMcontrolled method, (a) winding voltage and (b) winding current waveforms.

\section{Experimental results}

The proposed circuits in figures $2 \mathrm{a}$ and $3 \mathrm{a}$ are implemented by adding a sampling resistor and an ammeter in the load circuits. The items used in the experimental circuits are as follows:

Triac: MRC, BTB10 600B

Diac: DB3 C 836

Fast diodes $(D)$ : IXYS, DSE1 12-12 A

Diodes in the bridges: IXYS, DSE 35-12 A 820L

Condensator: $150 \mathrm{nF}, 63 \mathrm{~V}$ AC

Resistor $\left(R_{1}\right): 1.8 \mathrm{k} \Omega$

Variable resistor $\left(R_{2}\right): 10 \mathrm{k} \Omega$

Sampling resistor: $1 \Omega, 7 \mathrm{~W}$

IGBT: IXYS, IXGH 10N60AU1

We supplied the AC input voltage of $90 \mathrm{~V}$ via an auto-transformer because the driving motor was not operated during the experimental work. The current waveforms in steady-state operation are obtained via the sampling resistor with Lab-VIEW 1200 AI and a PC-based system.

In the phase-controlled circuit the winding current is controlled by varying the triggering angle of the triac. The steady-state waveform for the winding current of $1.94 \mathrm{~A}$ according to $\alpha=101^{\circ}$ is seen in figure 8 . The maximum and minimum current values obtained for various triggering angles and calculated current ripples are summarized in table 1 together with the simulation results. As may be seen in table 1, the simulation and experimental results are rather in agreement. 


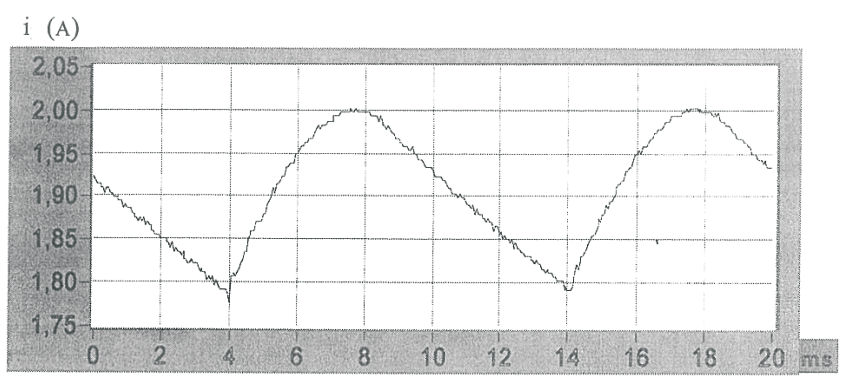

Figure 8. The experimentally obtained current waveform for $\alpha=101^{\circ}$ in steady state in phasecontrolled method.

The IGBT drive circuit in the PWM-controlled experimental circuit with a switching frequency of $2 \mathrm{kHz}$ is implemented by using a standard microcontroller (Intel 80C31). Figure 9 shows the steady-state waveform of the winding current for the case where its duty cycle is 0.52 . The experimental results obtained for different duty cycles can be seen in table 2 together with simulation results.

As it can be seen even from experimental results in table 2, the current ripples in the PWMcontrolled excitation circuit are lower than that in the phase-controlled circuit. There is good agreement from this viewpoint between the simulation and experimental results, verifying that the analysis made in this paper is correct. But there are some differences in the maximal and minimal current values between the simulation and experimental results. The reasons for these differences can be stated as follows:

1. Since the voltage drops in the semiconductor components in the analysis performed are neglected, in this configuration especially the voltage drop occurring on the IGBT causes the experimentally obtained current values to be low.

2. In the experimental work, the current peaks occurring cause $I_{\max }$ to be greater and $I_{\min }$ smaller. As a result of this, the current ripples are calculated to be greater.

3. Because of the turn-on times of the switching devices, the winding voltage waveform falls somewhat away from the real value of $(d)$.

\section{Conclusions}

This paper presents the implementation and test of the two proposed excitation circuits for a conventional arc welding converter. In the phase-controlled circuit, the current ripple depends on the winding current and reaches high values at small currents. In the PWM-controlled circuit, it is approximately independent from the winding current. The current ripples are

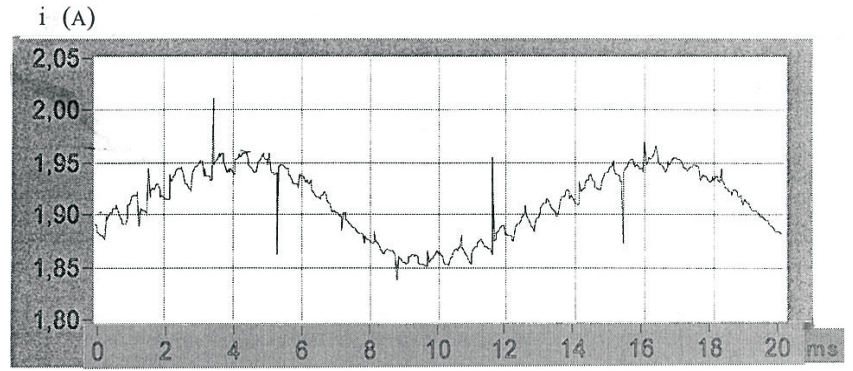

Figure 9. The experimentally obtained current waveform for $d=0.52$ in steady-state in PWMcontrolled method. 
principally within acceptable limits in both phase-controlled and PWM-controlled circuits for this application. But the PWM-controlled excitation circuit has a better performance. Both circuit configurations are used and found successful in this general-purpose welding converter. The components used in the phase-controlled circuit are simpler and more suitable for heavy environmental conditions, whereas the components used in the PWM-controlled circuit are more delicate and require better environmental conditions. In practice, one of the two excitation circuits can be preferred by considering the environmental conditions.

\section{List of symbols and abbreviations}

$\begin{array}{ll}d & \text { duty cycle; } \\ f & \text { supply frequency; } \\ f_{p} & \text { switching frequency; } \\ i & \text { winding current; } \\ I_{0} & \text { initial current; } \\ L & \text { inductance of excitation winding; } \\ R & \text { resistance of excitation winding; } \\ v & \text { supply voltage; } \\ v_{F} & \text { excitation winding voltage; } \\ V_{m} & \text { maximum winding voltage; } \\ \text { AC } & \text { alternating current; } \\ \text { CC } & \text { constant current; } \\ \text { CS } & \text { control range switch; } \\ \text { CV } & \text { constant voltage; } \\ \text { DC } & \text { direct current; } \\ \text { ER } & \text { excitation rheostat; } \\ \text { GMAW } & \text { gas metal arc welding; } \\ \text { GTAW } & \text { gas tungsten arc welding; } \\ \text { IGBT } & \text { Insulated gate bipolar transistor. } \\ \text { MA } & \text { magnetic amplifier; } \\ \text { PWM } & \text { pulse width modulation; } \\ \text { SMAW } & \text { shielded metal arc welding; }\end{array}$

\section{References}

Csaki F, Gansky K, Ipsits I, Marti S 1995 Power electronics (Budapest: Akad. Kiado) Electr. Eng. Handbook 1985 Electrical engineering handbook (New York: John Wiley \& Sons) Klingman D 1998 Learning to use new GTAW technology. Welding J. 77(9): 41-43

Miller D K 1999 What every engineer should know about welding procedures. Welding J. 78(8): 37-43

Mohan N, Undeland T M, Robbins W P 1995 Power electronics (New York: John Wiley \& Sons)

Sarul M H, Yildirmaz G, Gulgun R 2000 Measurement of the inductance of a coil with core at different currents by a DC chopper. Elect. Engng. (Archiv für Electrotech.) 82: 273-277

Stava E K 1999 The basics of GTA welding machines. Welding J. 78(8): 33-36

Thamodharan M, Beck H P, Wolf A 1999 Steady and pulsed direct current welding with a single converter. Welding J. (Welding Res. Suppl.) 78(3): 75-79

Weisman C 1976 Welding handbook 7th edn (Miami: Am. Welding Soc.)

Zhang S B, Zhang Y M 1998 A power source prototype provides multiple functions. Welding J. 77(9): 45-47 